ScIDice

International Journal of Forensic Science \& Pathology (IJFP)

\title{
Juvenile Terrorism in India
}

\author{
Case Study
}

Malini . $\mathrm{S}^{1^{*}}$, Yaseen. $\mathrm{MG}^{2}$

${ }^{1}$ Assistant Director, Forensic Science Laboratory, Bangalore, Karnataka, India.

${ }^{2}$ Senior Scientific Officer, Forensic Science Laboratory, Bangalore, Karnataka, India.

\section{Abstract}

Objectives: Perpetrators of terrorist offence often tend to be young children under the age of 18years. They are found engaged in a terrorist activity in different capacity. Terrorist groups often involve such children directly into terrorist act. Available literature has shown that children are more vulnerable than adults in the violent terrorist act owing to the lack of maturity and judgmental capacity. They are also found to have low level of guilt due to under arousal of autonomic nervous system activity.

Methods: In the present study 30 juvenile terrorist were brought to Forensic Science Laboratory, Bangalore from different parts of the country i.e Maharashtra, Karnataka and Andhra Pradesh. They were subjected to polygraph examination to measure changes in physiological parameters related to crime under investigation.

Results and Conclusion: Factors such as the age, education, family background, socio economic status, addictions were found to be having influence on the lower arousal of autonomic nervous system. The need of the hour is to identify the causes of juvenile terrorism and to create a reformative environment for the adolescent who conflicts with the law. In the present study, an attempt has made to explore psycho physiological factors underlying juvenile terrorism.

Keywords: Forensic Psychology; Psychophysiology; Juvenile terrorist; Polygraph; ANS.

\section{Introduction}

Juvenile crime or child crime refers to criminal acts by all those who are under 18 years of age. Certain children violating the settled social and legal rules often engage in criminal behavior known as juvenile crime. Juvenile Justice Act of 2000 has reported the minimum age of 7 years and the maximum age of 18 years for both the sexes. By definition, the Act of a child crime disturbing the social order and thus the application of the JJ Act of 2000 [1]. The records at the National Crime Records Bureau (NCRB) show a substantial rise in the child crime rate between 2010 and 2014 . Some cases like gang rape and murder of 2013, where in a juvenile played a major role had sent shocking waves in the nation.

Children's are the national assets. The parents and society must provide a healthy socio-cultural environment so that they could become responsible citizens physically and mentally. It is the state duty to ensure social justice. When children exhibit criminal acts it shows the disturbing trend in society. Millions of destitute children in India are from neglect and broken families they are malnourished, illiterate and sick. Research work has shown that millions of children are forced to work for a living when the children of their age are attending school. Psychologist in the area of juvenile crime had shown that juvenile living in poverty had shown a high level of aggression in their environment with improper parental care [2].

Juvenile behavior is a potential threat to society and individual development. Lombroso [3] has given environmental explanations in categorizing the criminals. He has categorized 4 types of criminals (i) Born criminals- atavistic characteristics people accounting for $1 / 3$ of all offenders (ii) Criminals by passion- people commit the crime for anger, love or honor or being propelled to crime by irresistible fears (iii) Insane criminals-as a consequence of an alteration in the brain unable to discriminate between right and wrong they commit the crime (iv) Occasional criminals-who does not require an occasion for the crime but almost drawn to even for insignificant reasons. These categories' include pseudo criminals, the crime for self-defense, criminal behavior stimulated by

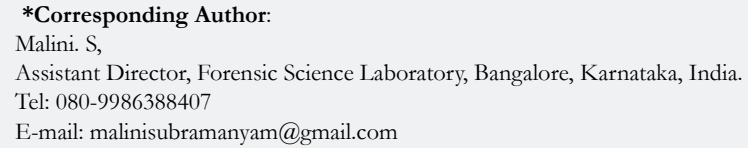

Copyright: Malini.$S^{\circ}$ 2021. This is an open-access article distributed under the terms of the Creative Commons Attribution License, which permits unrestricted use, distribution and reproduction in any medium, provided the original author and source are credited. 
environment circumstances or opportunities (v) Habitual criminals-regularly violate the laws as a part of their day to day life with little guilt or remorse.

Criminologist move towards the multifactor explanation of crime that includes not only hereditary factors but also socio, cultural and economic variables. Snyder [4] has concluded that young people violate the rules and disturb the social order thus attracting the attention of the police, court, prisons and law-abiding agencies. Juvenile terrorism is perceived as an imminent danger to society and to individual.

Terrorism is an act against the state, nation and also against civilization [5]. In spite of several laws to contain terrorism and related activities in developing countries, terrorism is rising in different forms. It is an act to terrorize individuals, communities, governments to conceding to their political demands. It is a form of psychological warfare. There are a various terrorist organisation. The terrorism goal is to disturb society by fear provoking and shattering safety of public and community . Terrorist target the entire nation and innocent civilians. In an effort to develop counter-terrorism act, the government has not given consideration to the fact that some of the alleged terrorists are children or juveniles under the age of 18 . Children who are arrested as terrorist suspect have confronted several dangers. In most of the countries court or judges are not specially designated to interrogate or deal with juvenile terrorist. There is no separate facility for juveniles in prison.

The application of justice to such children in conflict zones has emerged as a critical issue. The recent coalition's workshop in India has emphasized the way children are subjected to anti-terrorist legislation and emergent measures. The United Nations Convention of child right [6] forbids any capital punishment for a child under the age of 18 years. Article 37 (a) prohibit or eliminates corporal punishment and any other form of punishment degrading to the children below the age of 18 years. In India due to Increase of public pressure related to the Delhi gang-rape case, an amendment was proposed to Juvenile Justice Act of 2000. The amendment of the Juvenile Justice (Care and Protection of children) Act 2015 [7] suggest the trial for the age group of 16 to 18 years juveniles who have participated in horrifying crimes and offences. Neuroscientist and Psychologist have informed that below 18 years of age numerous changes in the body physiological, hormonal, emotional changes including structural changes take place. During this phase of life under arousal of physiological, hormonal, emotional functions likely to be responsible for the crime. Deviating thought process between the age group of 16 to 18 years shut the doors of their better reformation. The need of the hour is to identify the causes of juvenile terrorism and to create a reformative environment for the adolescent who conflicts with the law. In the present study, an attempt has made to explore psycho physiological factors underlying juvenile terrorism.

\section{Materials and Methods}

\section{Participants}

12 suspected juvenile terrorist from Maharashtra, 7 suspected juvenile terrorist from Karnataka and 11 suspected juvenile terrorist from Andhra Pradesh were brought to Forensic Science
Laboratory from the anti-terrorist squad of Maharashtra, special investigating team of Karnataka and Andhra Pradesh for the scientific examination of the Polygraph, Brain mapping and Narcoanalysis after obtaining from the permission of jurisdiction court. All experimental protocol for the above test was approved by the committee formed by the MHA government of India. The study was performed in accordance with the approved guidelines. Informed consent was obtained from all the participants prior to conducting this test. The participants were healthy suspected juvenile terrorist. Participants with problems related to physical health, mental health, addictions to the drug if any excluded from the study to prevent the contamination of the obtained results. The questionnaire was also administered to identify the personal details like age, education, gender, history of past illness, affiliation to any organization/organisations, history of a past crime, history of crime in the family members, punishment undergone if any, socio-economic status of the family, addictions if any in the suspected terrorist. Each participants hearing and visual check was obtained. Participants with normal IQ were selected by administering Binet Kamat tests of Intelligence. During the preliminary interaction this juvenile terrorist was found to be affiliated to terrorist organization. Most of the juvenile terrorist reported affiliation of one or two members of their family with the terrorist organization. The Juvenile terrorist was administered Mini-mental status examination to evaluate their present mental status. The personal details of each juvenile terrorist were obtained during the preliminary interaction stage.

\section{Procedure}

Scientific methods used to investigate the adult terrorist were found effective to the juvenile terrorist. One of the detections of deception test called polygraph test is used by the experts from the Forensic Science Laboratory, by the Police and the Government agencies to assess the juvenile suspect's truthfulness to evaluate and to accept their parole. Research on polygraph technique by Honts, Raskin \& Krisher 2006 [7] has shown the polygraph method to be highly reliable and valid for detecting the deception and verifying the veracity of the statement of the suspects regarding crime under investigation. However only few research studies are found available in the use of the polygraph for assessing the deception in juveniles.

Polygraph examination was conducted in the present study to assess the truthfulness or lying pattern of the juvenile terrorist. Polygraph testing is based on the principle that the brain sends a signal to the body and physiological changes are noticed when the question related to the crime under investigation is asked. These bodily changes are involuntary in nature and are automatically controlled by the autonomic nervous system. During an emotionally aroused state increase in the heart rate, respiration rate, blood pressure was noticed. In polygraph examination these physiological changes, for a question the subject is deceptive is different for those question that shows normal response. Polygraph examination [8] measures changes in respiratory system, electro dermal system and cardiovascular system in graphical form. Bodily changes occurring in response to crime and investigation is recorded graphically.

\section{Components of the Polygraph}

a. Pneumograph measures the respiratory pattern of inspiration 
and expiration while subject response to relevant questions. This component of the polygraph has two rubber tubes with beads to fasten around the chest region and another to abdominal region to measure the breathing pattern.

b. Electro dermal response measures skin resistance level or skin conductance level in response to the relevant questions. Galvanic skin response or Galvano graph is one of the important components of the polygraph examination. Two electrical sensors are attached to the fingertips of the subject. The electro dermal response is also called a galvanic skin response or the skin potential response.

c. Cardio-vascular activities are measured using cuff similar to the measurement of BP by fastening around the upper arm. A Finapres blood pressure monitor was used to record the BP by placing a finger cuff on the middle phalanx of the third finger in the left hand. Finapres in the present study was found to be more comfortable for juvenile delinquents.

On arrival of suspected juvenile terrorist to the Forensic Science Laboratory, Bangalore detail history was collected. Relatives who accompanied the juvenile terrorist were also interacted with. The relatives on request were allowed to stay in the polygraph examination room to help the juvenile terrorist in adjusting to the polygraph testing environment and to establish the rapport with the examiner.

Questionnaires were formulated on the basis of the information provided by the anti-terrorist squad, special investigating team and statement by suspected juvenile terrorist and information obtained by the relatives. Control question technique was used which consist of a mixture of relevant and irrelevant question. Initially the normal physiological parameters of the suspects were recorded prior to the administration of the questionnaire. All the questions were reviewed with the suspects and they were instructed to answer the question is yes or no format. Problems in understanding the questions were clarified, the suspected juvenile terrorist was reminded that if the answer is truthful there would be no change in their body if they were lying there would be changes observed. Any doubts raised by juvenile terrorist or the accompanying parents were answered at this time. The review of the questionnaire revealed whether the suspects were able to understand the questions properly, whether they were able to answer in yes or no to all the questions. The questionnaire was administered 3 times. In the post polygraph examination state normal recording of physiological function were completed.

\section{Results}

\section{Analysis of the data}

For each physiological measures, three repeated trial of the question sequence yielded a set of 18 discrete measurements of respiration responses, skin conductance and blood pressure responses. Any unwanted changes noticed during the recording were eliminated using artefacts elimination programme. Artefacts like body movements in the present study were due to adjustment of the suspected terrorist to the recording equipment. The entire procedure of polygraph examination was video recorded. The polygraph examiner verified the body movement by looking into the video recording of the examination. The amplitude of skin conductance, blood pressure and variations in the respiratory pattern were identified. Largest amplitude in relative unit was identified and distances from the base to the peak was measured. The largest peak was selected for the analysis. The blood pressure means curve were calculated by looking into the amplitude. In the respiratory parameter, average respiration was measured by measuring the vertical distance between two adjacent samples following the onset of question for 10 seconds. The same method was adapted for thoracic and abdominal channels of respiration. These 3 physiological measured were evaluated individually for each trail for diagnosing the truth and deception response. The variation in each physiological measure was scored. The physiological variations in each parameter were scored using a 7 point scale. +3 positive score was indicative of truthfulness and -3 a negative score was indicative of guilt.

\section{Discussion}

The information collected during preliminary interaction and information obtained through polygraph examination were analysed for better understanding of the factors such as age, education, socio-economic status, association with terrorist organizations, addiction if any contributes for psycho physiological over/ under arousal in suspected juvenile terrorist. Electrodermal under activity has been reported in studies related to antisocial delinquent, hyperactive or aggressive children. The poor electrodermal response reflects poor behavioural inhibitions especially aggressive conduct disorder. Quay 1965 [9] says that autonomic under activity produces a lower than optimal level of arousal (Normal level) that in turn causes juvenile to search for stimulation seeking behaviour. He has further contributed to sub-grouping childhood disorder as psychopathic delinquency/ Neurotic delinquency and sub-culture delinquency.

The present study is an attempt to explore the developmental factors of age that influenced the detection of deception in the polygraph examination of the suspected juvenile terrorist in table 1. The average age of the suspected juvenile terrorist selected for this present study was between 14 to 18 years. The participants were belonging to Maharashtra, Karnataka and Andhra Pradesh. It has been observed from the table 1 , that $31 \%$ of the suspected juvenile terrorist were found to be between the age group 14 to 15 years, 35\% suspects were between 16 to 17 years and $34 \%$ of them were 18 years of age. These participants were in transition from childhood to adolescents and uncertain about themselves, unable to take proper decision and unable to manage life in a proper way. With the newly found autonomy doubtful of themselves and they were more susceptible to the social influence of the organized group. Russel and Miller [10] have found that the average age of an active terrorist member was between 22-25 years except for Palestinian, German and Japanese terrorist who was found between 20 and 25 years old. Taylor (1988) [11] characterises demography of International terrorist as being in there early 20's and unmarried. He also had noticed that there is considerable variability from group to group. Age trends for many terrorist groups such as LTTE were having members in the age group $16-17$ years age level and even some members were preteens. Walter Lacquer [12] had noted that Arab and Iranian group had used the boys between 14 to 15 years of age for the dangerous mission. In the present study suspected juvenile terrorist falls 
Table 1. Shows age group of the suspected juvenile terrorist.

\begin{tabular}{|c|c|c|}
\hline S1 No & Age & No of Suspects \\
\hline 1 & $14-15$ & 9 \\
\hline 2 & $16-17$ & 11 \\
\hline 3 & 18 & 10 \\
\hline
\end{tabular}

Table 2. Indicates the level of education suspected juvenile terrorist delinquents.

\begin{tabular}{|c|c|c|c|}
\hline \multirow{2}{*}{ Education } & Maharashtra & Karnataka & Andhra Pradesh \\
\cline { 2 - 4 } & Juvenile & Juvenile & Juvenile \\
\hline Less than 5th class & 6 & 1 & 6 \\
\hline School drop out & 3 & 2 & 4 \\
\hline More than 5th Class & 2 & 3 & - \\
\hline Never attended school & 1 & 1 & 1 \\
\hline Total & 12 & 7 & 11 \\
\hline
\end{tabular}

into age group similar to LTTE, Arab and Iranian group as available in the literature. In this study in the above-mentioned age group, they are less likely to ask the question, follow instructions given and are less likely to attract attention in their accomplishment of the target. The present study score of -1 in all relevant questions suggests that under arousal of responses in GSR low skin conductance, under arousal of $\mathrm{BP}$ has been linked with antisocial and impulsive behaviour in juveniles between the age group of 13 to 18 years. Further the present research has also indicated poor behavioural, cognitive and social adjustment as well as poor self-regulation. The suspected juveniles were instructed by their leaders of the terrorist group in the present study to assist in the assemble of bombs, to assist in purchase of material, accompanying them to visit the target place prior to the accomplishment of the task. They were also supplying tea, coffee and food items. These suspected juvenile terrorists followed instructions given by their leader without questioning them. They never felt guilty or shame for accomplishment of these tasks due to low cortical arousal and increased peer pressure.

From the Table 2 level of education of suspected juvenile terrorist were classified as school dropouts, less than 5th class, more than 5th and those who never attended the school from the regions of Maharashtra, Karnataka and Andhra Pradesh. In the present study majority of the suspected were less than 5 th class contributing to $43 \%$ of the total population found scoring -1 in GSR, BP and Respiratory channel thus indicating low cortical arousal to the relevant questions in the polygraph. They have dropped out before completion of elementary education. Children who were dropped out of the school were $30 \%$, only $17 \%$ of the juvenile had schooling more than 5 th class and their scoring was -2 in GSR and Respiration channel indicating lower cortical arousal. Children who never attended the school were 10\%. Less than 5 th class were found more in number in Maharashtra and Andhra Pradesh than in Karnataka Region. School dropouts were more in Andhra Pradesh than compared to the other two regions. In the present study even those who never attended the school were found to be literates i.e. able to read and write. Research carried out in the area of juvenile crime has found positive association between crime and academic achievement. Suspected Juvenile terrorist were found lower in their academic achievement when compared to same-age peers. Further school dropout was also the responsible factor for maintaining delinquent behaviours in present study juveniles. A research Glueck and Glueck (1950) [13] have found that juvenile delinquents nearly 85 per cent of them were behind academically when compared to their peers. Recent research have also found that failure to develop higher level of reading and writing skills. US Bureau of justice in 1997 has suggested that 70 per cent of juvenile delinquents reading and writing skills are below 4th-grade level. Foley (2001) [14] work found that reading level of juvenile delinquents was between fourth and seventh grade significantly below the expected level for the age. Some of the research findings had established a link between academic achievement levels to the severity of the offence, suggesting those who engage in violent crimes display higher academic deficits when compared to those engaging in non-violent crimes. Related to these findings research has shown that a significant percentage of youth have exhibited education disability in the juvenile justice system. Blomberg, Bales and Piqeuro (2012) [15] studied academic achievement in 4146 delinquents and found that average academic achievement subjects were found to return to school after they were released and further they were less likely to be in one-year post-release period get re-arrested. The Defoe et al (2013) [16] proposed in their study, that academic achievement should be focused primarily for interventions with juvenile delinquents because of the significant relationship between low achievement and delinquency. Adolescent between 16-18 years were found to be more involved with juvenile justice system than those who attended the school in the present study, Less than 5th class were reported their involvement in crime more than those who continued education after 5 th class. Suspected juvenile terrorists who belong to the school dropouts and never attended school were found to be affiliated and identified themselves more with the terrorist organization. In this study suspected juvenile terrorist associated with the poor school achievement have found to fall further behind in school, had less reason to stay bonded to school and less strive for academic achievement. Further they reported that failure in school had narrow down their employment opportunity at the same time the peer support for criminal activity had become more dominating. Due to low academic achievement, poor electro dermal response were noticed reflecting poor behavioural inhibitions. Poor school performance for the suspects in the present study has lead to development of frustration, anger and subsequently delinquent behaviour. 
In the present study with reference to table 3 , large numbers of suspected juveniles about $43 \%$ were found belonging to the family with the history of alcoholism or prolonged alcohol problems. This was the major factor for the suspected juveniles in the present study to join the terrorist activity. With the loss of parental control they had become easy prey for the terrorist activity with no one to guide them or direct them. $40 \%$ suspected juvenile terrorist were belonging to the family of a single parent. Some of the juveniles were born out of wedlock ie unmarried mothers and some reported that their fathers were separated from their life, divorced and $17 \%$ were orphans. In all these groups less than -2 scores in GSR, BP indicated poor parental monitoring, supervision and poor social skills were the contributing factor for the lower cortical arousal. Some of the juveniles reported family history of involvement in many types of crime. Thus the hereditary factors were found to be positive in all theses juveniles in the emergence of criminal behaviour. Upbringing of the child with the history of childhood abuse, neglect and violence due to alcoholic parents developed impulsive and aggressive behaviour in children. They were incapable of developing sense of right and wrong, expressed their inability of controlling revenge, anger, aggression and had fallen into the prey of criminals. The parental personality disorder had an effect on the development in child mind. Leaving in the family of alcoholics, watching violence the juvenile had soon started learning criminal behaviour as it was no longer perceived crime as a punishable or guilt. Such juveniles in unprotected environment reported no taboo or guilt to engage in crime related to terrorism showed low arousal in all the parameters of polygraph and anticipated no punishment. According to Eysenck [17] children who do not anticipate punishment shows lower cortical arousal. Studies have found that more than $60 \%$ of juvenile criminals have history of family involvement in crime. Studies have also reported history of physical abuse by alcoholic parent, violent offending behaviour as responsible for delinquent behaviour. David Rowe [17] describes low arousal theory in terms of fearlessness - lack of fear predisposes towards the crime and they have difficulty to socialize.

Table 4 indicates that majority i.e. $80 \%$ of juvenile terrorist belonging to a low socio-economic group. The most reliable factor for joining the terrorist group by the juveniles is the financial status of the family. In the present study, more than $2 / 3 \mathrm{rd}$ of the suspected juvenile terrorist comes from low socioeconomic status. Only $20 \%$ of (i.e 06 ) of them were from middle socioeconomic status background. The main reason for the school drop out in the present study as expressed by the juveniles is the financial need. Research findings have shown a significant correlation between juvenile offenders and low socio-economic status. Strain theory and Social Control theory has explained low socio-economic status as an impact factor on juvenile delinquency. Some researchers have also indicated the economic background as the

Table 3. Indicates the family background of suspected juveniles.

\begin{tabular}{|c|c|c|c|c|c|c|c|c|}
\hline \multicolumn{3}{|c|}{ Maharashtra } & \multicolumn{3}{c|}{ Karnataka } & \multicolumn{3}{c|}{ Andhra Pradesh } \\
\hline $\begin{array}{c}\text { Single } \\
\text { Parents }\end{array}$ & $\begin{array}{c}\text { Parents } \\
\text { with H/O } \\
\text { Alcoholism }\end{array}$ & Orphans & $\begin{array}{c}\text { Single } \\
\text { Parents }\end{array}$ & $\begin{array}{c}\text { Parents } \\
\text { with H/O } \\
\text { Alcoholism }\end{array}$ & Orphans & $\begin{array}{c}\text { Single } \\
\text { Parents }\end{array}$ & $\begin{array}{c}\text { Parents } \\
\text { with H/O } \\
\text { Alcoholism }\end{array}$ & Orphans \\
\hline 4 & 5 & 3 & 5 & 2 & --- & 3 & 6 & 2 \\
\hline
\end{tabular}

Table 4. Shows Socioeconomic status of suspected Juvenile terrorist.

\begin{tabular}{|c|c|c|c|c|c|c|c|c|}
\hline \multicolumn{3}{|c|}{ Maharastra } & \multicolumn{3}{c|}{ Karnataka } & \multicolumn{3}{c|}{ Andhra Pradesh } \\
\hline Lower & Middle & Higher & Lower & Middle & Higher & Lower & Middle & Higher \\
\hline 10 & 2 & - & 6 & 1 & - & 8 & 3 & - \\
\hline
\end{tabular}

Table 5. Showing Addictions of suspected juvenile terrorist.

\begin{tabular}{|c|c|c|c|c|c|}
\hline \multicolumn{2}{|c|}{ Maharashtra } & \multicolumn{2}{c|}{ Karnataka } & \multicolumn{2}{c|}{ Andhra Pradesh } \\
\hline $\begin{array}{c}\text { Binge TV } \\
\text { watching }\end{array}$ & $\begin{array}{c}\text { Smoke Oc- } \\
\text { casionally }\end{array}$ & $\begin{array}{c}\text { Binge TV } \\
\text { watching }\end{array}$ & $\begin{array}{c}\text { Smoke Oc- } \\
\text { casionally }\end{array}$ & $\begin{array}{c}\text { Binge TV } \\
\text { watching }\end{array}$ & $\begin{array}{c}\text { Smoke Oc- } \\
\text { casionally }\end{array}$ \\
\hline 11 & 1 & 5 & 2 & 10 & 1 \\
\hline
\end{tabular}

Figure 1. Chart represents education level percentage of suspected Juvenile delinquents.

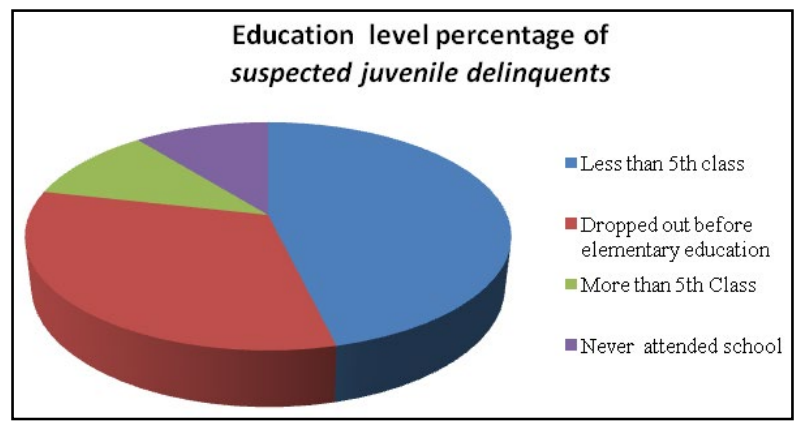


Figure 2. Chart represents family background percentage of suspected Juvenile delinquents.

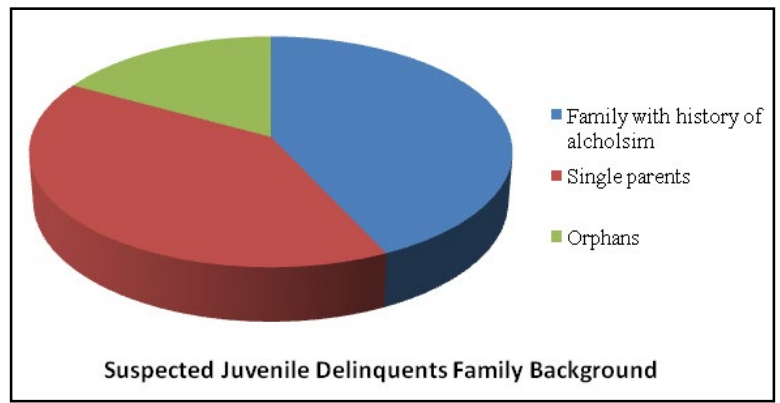

Figure 3. Chart represents Socio-economic status level percentage of suspected Juvenile delinquents.

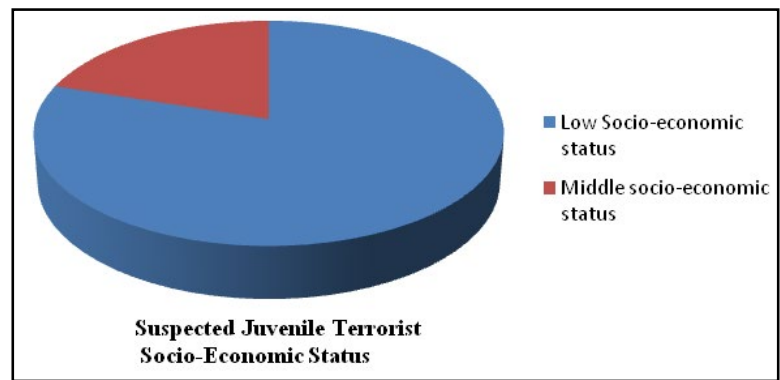

Figure 4. Chart represents Karnataka state addiction level percentage of suspected Juvenile delinquents.

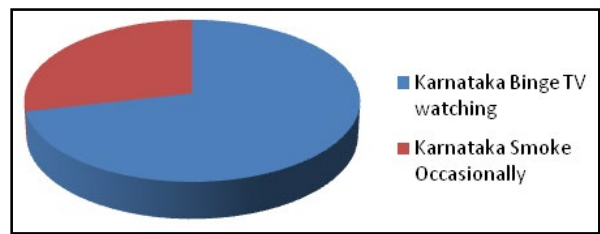

Figure 4 (a). Chart represents Maharashtra state addiction level percentage of suspected Juvenile delinquents.

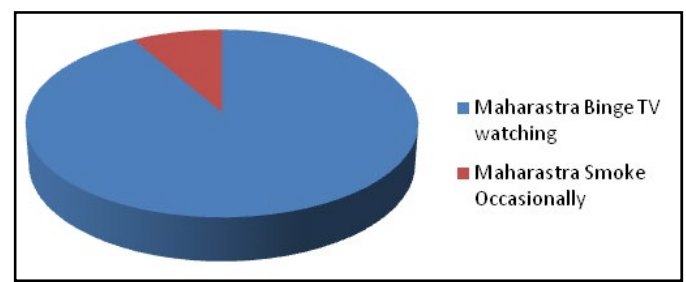

Figure 4 (b). Chart represents Andhra Pradesh state addiction level percentage of suspected Juvenile delinquents.

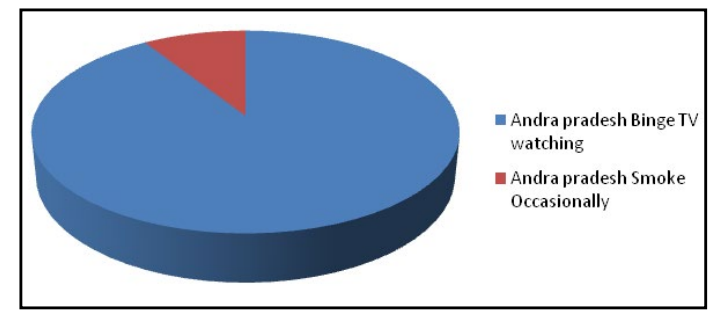

best indicator for juvenile delinquency. Some researchers Richard E Tremblay (1997) [18] have indicated poverty having a direct relationship with low academic achievement in juvenile crime. In the present study low socioeconomic status was the primary risk factor for committing terrorist activities as a result poor cortical arousal. In research study, Badami (1965) [19] had considered broken homes along the factors, such as poverty, disorganized family, family conflicts, and abused children to be the important factors causing juvenile delinquency. The same factors were found contributing to the juvenile terrorism in the present study. In the present study suspects have reported the loss of proper supervision, guidance and support by the family to assure their conformity to societal rules. Anti-social acts of neighbourhood, family members under aroused juvenile delinquents and developed fearlessness to carryout the anti-social acts. Emotionally under aroused juveniles experience little or no restraint. The low level of autonomic arousal and fearlessness to carry out such acts were responsible in maintaining such behaviour. In the present study the leaders and sleeping commando's were either one of the member of the family or the member of their neighbourhood. To carry out the assigned task juveniles help were sort. Training was given for various period ranging from four months to two years before the mainstream tasks were assigned to them. Juvenile and the family members were provided with the financial assistance by this group. Suspected juveniles reported financial assistance as a major factor in assisting them in task accomplishment.

In the present study table addiction to drug was an exclusion cri- 
terion to avoid the contamination of the result. From the table 5 , it can been seen that $2 / 3$ rd of the suspected juvenile terrorist were addicted to the TV watching for long hours. On enquiry they have revealed that they enjoy watching violent related TV programme and due to low cortical arousal they did not regard watching violent actions as crime. Contribution of media in promoting terrorism cannot be ignored. The method, the actions and the goals of a terrorist through media are quickly made known to the potential terrorist. Juvenile terrorist reported to have inspired by the action of terrorist and was trying to imitate them. Smoking was the other addiction reported by $1 / 3 \mathrm{rd}$ of the suspected terrorist. Children with single parents and orphans were reported to have developed this addiction due to greater autonomy, less parental control and increased susceptibility to peer pressure. The weaker family relationship, rejection in the family, absence of supervision influences the child perception of self and affects the addiction behaviour. Juvenile terrorists have shown a lack of anxiety and guilt in doing wrong things. The arousal theory has suggested that autonomic under arousal is due to low emotionality, lack of empathy and ability to lie quickly and easily. The suspected juveniles were found to be emotionally immature with lack of judgemental capacity, lack of responsibility, deceitful, manipulative, unemotional, impulsiveness, irresponsible but had the ability to rationalize and justify behaviour. This study of suspected juvenile terrorist has found that juveniles are more inclined to continue the life of crime than normal arousal state.

\section{Conclusion}

From the present study, it has been identified that juvenile terrorists have various motivation and inclination for the specific act thus leading to the process of radicalization the present study.

In the present study majority of juveniles had problems related to families, problem parents, low educational achievement, low socio economic status, poverty as the major factors resulting in under development of emotional arousal and under development of moral values. In the present study suspects affiliated to LET and SIMI organizations were examined. It was found that the revenge seekers, status seekers, identity seekers, thrill-seekers are some of the motivating factors in joining and maintaining Terrorism. Terrorism is a great threat for the developing and developed nation. Thus it is important to understand and analyze different variables that are responsible for the development and maintenance of juvenile terrorism. The present study has shown a positive relationship between low skin conductance to aggressiveness and anti-social behaviour which has led them to develop ability to lie easily and quickly. Low heart rates are further link to higher rates of criminal anti-social behaviour especially violence with this suspected terrorist. Sympathetic activity were found more in cardio channel and electro dermal channel. Thus the findings in the study skin conductance and heart rate are characterized by under arousal of the autonomic nervous system.

There is an urgent need to fight against juvenile terrorism. By looking into the terrorist, it can be concluded that injustice, belongingness, autonomy and heroism are the real psychological motivation and has a strong influence of this juvenile in joining and identifying with the terrorist group. An effort has been made in the present study to improve counter-terrorism policies by clarifying how each individual juvenile terrorist view the world, the main contribution in this study is understanding psychological needs of each individual. By Counselling and providing guidance, by improving communication pathways in the families it is possible to reduce the number of juveniles who are highly susceptible to radicalization. Counselling juveniles to reduce their negative emotions of aggression and counselling parents for positive parenting helps to improve psycho-social variables.. Ananth Kumar Astana [20], an advocate from Delhi high court has suggested the government a change in the juvenile justice system. He has said that the amendment by the government is not justice to the juvenile. Some measures that may help in reforming juvenile terrorist are making them develop a sense of security and give them affection and love that they are been deprived of. Their parents / caretakers should be counselled to detect prior signs of maladjustments and also tendency which is heading towards in juvenile for terrorist act should be destroyed at the roots. It is the duty of every parent, friends, teacher, relative to mould and guide the new generation to the correct path.

\section{References}

[1]. Juvenile Justice (Care and Protection of Children) bill Prelegislative research, Institute of Policy Research Studies, New Delhi. 2014.

[2]. Anneli Botha. Root causes of violent extremism and Terrorism, [Doctoral Dessertation], University of Free State. 2014.

[3]. Ceasre Lomborso. Theory of Criminology, exploring young mind.com 2019.

[4]. Snyder HN. Juvenile offenders and victims: National report. National Center for Juvenile Justice; 2006.

[5]. Cohen EA. Terror in the Mind of God: The Global Rise of Religious Violence. Foreign Affairs. 2000 May 1;79(3):166.

[6]. Office of United Nation High Commission of Human Rights, Human Rights Terrorism and Counter terrorism, UNO, Geneva, Switzerland, ISSN-10145567

[7]. DC Raskin. Study of the validity of the polygraph examination in criminal investigation (research) Report, NCJRS, USA. 2006.

[8]. Kircher JC, Raskin DC. Computer methods for the psychophysiological detection of deception.

[9]. Arnett PA. Autonomic responsivity in psychopaths: A critical review and theoretical proposal. Clinical Psychology Review. 1997 Dec 1;17(8):903-36.

[10]. Russell CA, Miller BH. Profile of a Terrorist. Studies in conflict $\&$ terrorism. 1977 Jan 1;1(1):17-34

[11]. Taylor DM, Louis W, Terrorism and the quest for identity, edited by R. O. Slater and M. Stole. Basingstoke, Hampshire. 2004.

[12]. Walter Laqueur. Work on terrorist (Vol 3). Sage Publication. 1998; 2040 2042.

[13]. Richard L. Levine. Gluecks Pioneer in delinquency Study. Thecrimpson. com. 1963.

[14]. Foley RM. Academic characteristics of incarcerated youth and correctional educational programs: A literature review. Journal of emotional and behavioral disorders. 2001 Oct;9(4):248-59.

[15]. Bloom W. Personal identity, national identity and international relations. Cambridge: Cambridge University Press.

[16]. Defoe IN, Dubas JS, Dalmaijer ES, van Aken MAG. Is the Peer Presence Effect on Heightened Adolescent Risky Decision-Making only Present in Males? J Youth Adolesc. 2020 Mar;49(3):693-705. Pubmed PMID: 31863339.

[17]. Bartusch DJ, Burfeind J. Juvenile Delinquency: An Integrated Approach.

[18]. Tremblay RE, Craig WM. Developmental juvenile delinquency prevention. European Journal on Criminal Policy and Research. 1997 Jun;5(2):33-49.

[19]. Priyanka Yadav. Juvenile Delinquency as a behavioral problem, International Journal of Indian Psychology. 2016 4(1):76.

[20]. Adenwalla M, Raha S, Asthana AK. Handbook for Advocates Working with Children in Conflict with Law in India Under The Juvenile Justice (Care and Protection of Children) Act, 2015 \& The Juvenile Justice (Care and Protection of Children) Model Rules, 2016. Centre for Child and the Law, National Law School of India University; 2018. 